\title{
Severe acute pancreatitis: surgical indications and treatment
}

\author{
Max Heckler $^{1}$ (D) $\cdot$ Thilo Hackert $^{1}$ (D) $\cdot$ Kai Hu ${ }^{1} \cdot$ Cristopher M. Halloran $^{2}$ (D) $\cdot$ Markus W. Büchler $^{1} \cdot$ \\ John P. Neoptolemos ${ }^{1}$ (D)
}

Received: 11 July 2020 / Accepted: 21 July 2020 / Published online: 10 September 2020

(C) The Author(s) 2020

\begin{abstract}
Background Acute pancreatitis (AP) is defined as an acute inflammatory attack of the pancreas of sudden onset. Around $25 \%$ of patients have either moderately severe or severe disease with a mortality rate of $15-20 \%$.

Purpose The aim of this article was to summarize the advances being made in the understanding of this disease and the important role of surgery.

Results and conclusions An accurate diagnosis should be made a soon as possible, initiating resuscitation with large volume intravenous fluids and oxygen by mask. Predicted severe disease will require intensive monitoring. Most deaths within the first week are due to multi-organ failure; thus, these patients will require intensive therapy unit management. During the second phase of the disease, death is due to local complications arising from the pancreatic inflammation, requiring accurate identification to determine the correct form of treatment. Acute peripancreatic fluid collections arise $<4$ weeks after onset of interstitial edematous pancreatitis, not requiring any treatment. Most pancreatic pseudocysts arise $>4$ weeks and largely resolve on conservative management. Necrotizing pancreatitis causing acute necrotic collections and later walled-off necrosis will require treatment if symptomatic or infected. Initial endoscopic transgastric or percutaneous drainage will resolve less serious collections but necrosectomy using minimally invasive approaches will be needed for more serious collections. To prevent recurrent attacks of AP, causative factors need to be removed where possible such as cholecystectomy and cessation of alcohol. Future progress requires improved management of multi-organ failure and more effective minimally invasive techniques for the removal of necrosis.
\end{abstract}

Keywords Pancreatic necrosis $\cdot$ Infection $\cdot$ Minimally invasive surgery $\cdot$ Necrosectomy $\cdot$ Endoscopic $\cdot$ Percutaneous

\section{Introduction}

\section{Etiology, incidence, financial aspects}

Acute pancreatitis (AP) is defined as an acute inflammatory attack of the pancreas with a sudden onset of symptoms, which, in the absence of post necrotic damage to the gland, results in complete resolution of histology, physiology, and symptoms and provided the initiating cause is removed there will be no further attacks. The commonest causes for AP are gallstones (40-65\%) and alcohol (25-40\%), and the

John P. Neoptolemos

john.neoptolemos@med.uni-heidelberg.de

1 Department of General, Visceral and Transplantation Surgery, University of Heidelberg, Im Neuenheimer Feld 110,

69120 Heidelberg, Baden-Württemberg, Germany

2 Department of Molecular and Clinical Cancer Medicine, University of Liverpool, Liverpool, UK remainder (10-30\%) are due to a variety of causes including autoimmune and genetic risk factors (Table 1) $[1,2]$. Irrespective of etiology, the trigger factors cause supraphysiological intracellular signaling resulting in trypsin activation within the zymogen granules [3-5]. The resultant acinar cell death causes a localized and systemic inflammatory response. Initially, the most prominent features are distant organ dysfunction notably the lungs and kidneys, which in most cases is of short duration $(<48 \mathrm{~h})[6,7]$.

The incidence of AP is rising globally with an estimate of 34 cases (95\% confidence interval (Cl) 23-49) per $10^{5}$ general population per year [8]. In Europe, the incidence of AP ranged from 4.6 to 100 per $10^{5}$ population and was the highest in eastern and northern Europe [9]. In the USA, there were approximately 275,000 hospitalizations in 2009 , almost doubling from that in 1988 [2]. Longitudinal data from Japan demonstrate a threefold increase from 1998 to 2011, with a prevalence of 49.4 per $10^{5}$ [10]. Lifestyle factors probably account for the rising incidence, which can be attributed to diet and gallstones, alcohol and smoking consumption, 


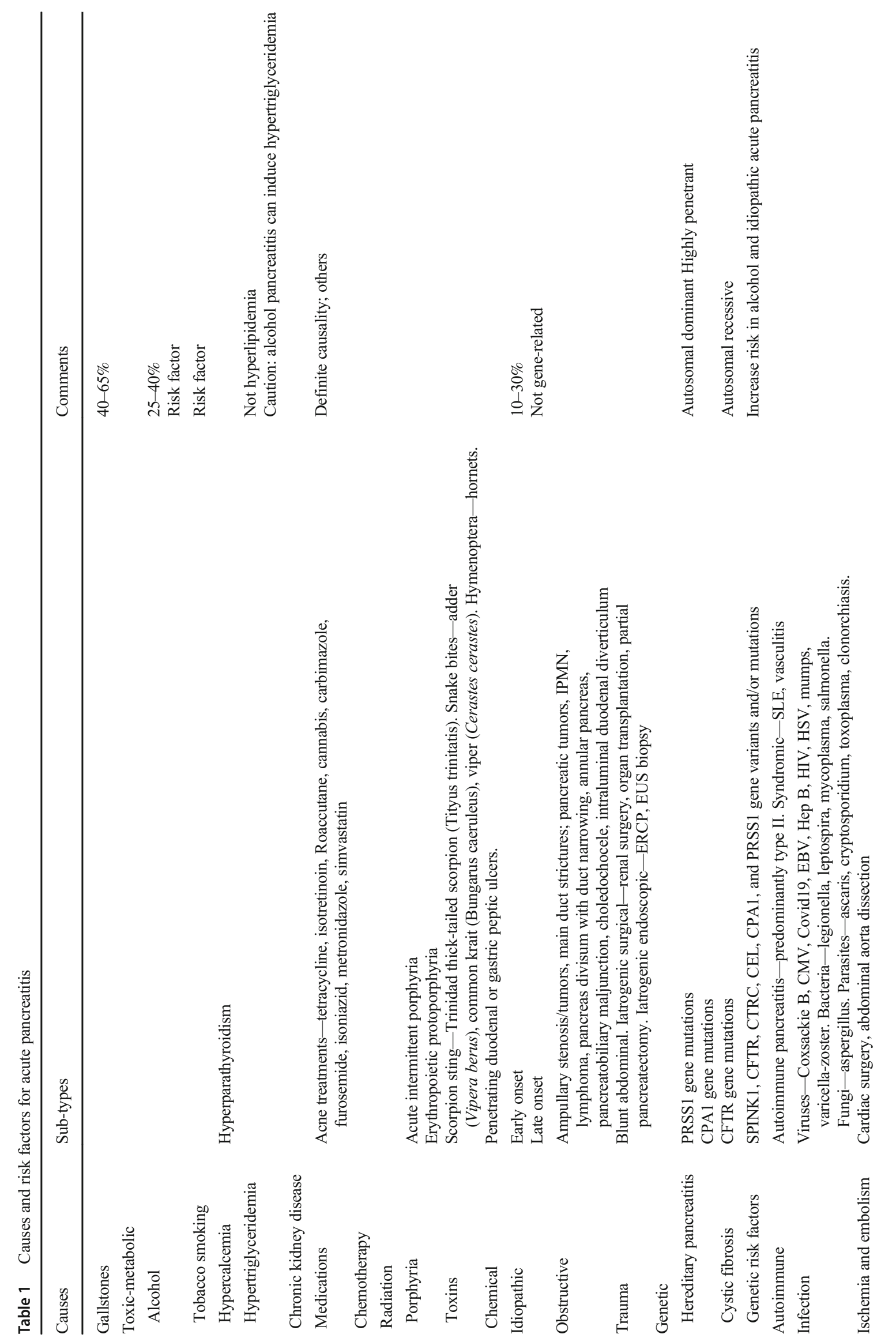


diabetes mellitus, and obesity [2]. The overall financial burden of AP on public health systems across the world is considerable. A USA study from 2007 estimated \$2 billion for hospitalization for AP - around $\$ 10,000$ per admission [11]. Timely identification of patients at risk for developing severe disease and a state-of-the-art treatment of these patients are multidisciplinary challenges.

\section{Classification and severity}

Around $75 \%$ of cases of AP have a mild clinical course and are self-limiting, usually only requiring intravenous fluids with oxygen support by mask [7]. The remaining patients are classified as having either moderately severe or severe disease with a mortality rate of 15-20\% [12-15]. Persistent organ failure beyond $48 \mathrm{~h}$ is the major cause of morbidity occurring in around half of the patients with pancreatic necrosis and in up to two-thirds of those with superimposed infection [12-15]. Pancreatic necrosis develops in approximately $20 \%$ of patients, with infection of the pancreatic necrosis occurring in $30-70 \%$ of patients resulting in a mortality rate of $20-30 \%$ [13-16]. Fungal infection may occur secondarily to bacterial infection and is associated with high mortality in primary and secondary infected pancreatic necrosis, requiring aggressive systemic anti-fungal therapy [17]. There are two phases of mortality, the major cause of death in the first week being continuing multiple organ failure, while most deaths in the subsequent period are due to local pancreatic necrosis (Fig. 1). In a systematic review and meta-analysis totaling 6970 patients, the mortality rate in patients with infected necrosis and organ failure was $35.2 \%$, compared with $19.8 \%$ for sterile necrosis with organ failure and $1.4 \%$ for infected necrosis without organ failure [18].

The revised Atlanta classification published in 2012 provides a well-established framework for the stratification of AP patients with precise definitions of complications and severity

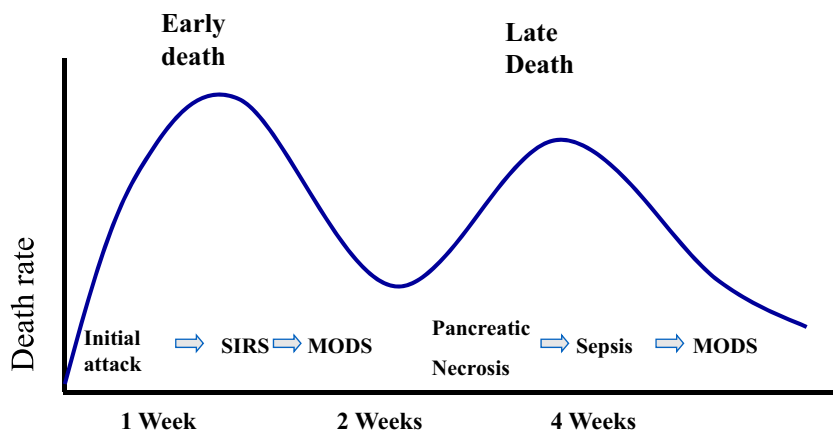

Fig. 1 Distribution of deaths in patients with severe pancreatitis. Most deaths occur in the first week or so from multi-organ dysfunction syndrome (MODS) consequent to an excessive systemic inflammatory response syndrome (SIRS). In the second phase, deaths tend to occur from pancreatic necrosis and are associated with sepsis, leading to secondary MODS shown in Table 2 [12]. Correct identification of the nature of the local complication is important for clinical decision-making. The Determinant-Based Classification provides an additional Critical Severity Grade defined as a combination of both infected pancreatic necrosis and persistent organ failure, but is not as widely used as the revised Atlanta [19]. The recommendations of the IAP/APA evidence-based guidelines for the management of acute pancreatitis incorporate the 2012 revised Atlanta classification and are summarized in Table 3 [20].

Rapid diagnosis and prediction of severity are critical to provide fluid resuscitation and oxygen supplementation and intensive care for patients in need. The diagnosis requires at least two of the following three criteria: acute onset upper abdominal pain, serum amylase or lipase $>3 \mathrm{x}$ upper limit of normal, and/or imaging with contrast-enhanced CT or MRI. The revised Atlanta classification recommended the Modified Marshall scoring system for organ dysfunction that incorporates the renal, respiratory, and cardiovascular status of the patient, is easy to assess, and can be repeated daily [21]. Although the revised Atlanta classification recommended a systemic inflammatory response syndrome (SIRS) score of $\geq 2$ for severity prediction, this is no better than the clinically pragmatic and robust modified Glasgow system and serum CRP levels [12, 22, 23].

\section{Treatment strategies}

Resuscitation with intravenous fluids, supplemental oxygen and close monitoring are essential from the outset of the attack. In gallstone AP, endoscopic retrograde cholangiopancreatography (ERCP) and consecutive gallstone removal and sphincterotomy are indicated in patients with cholangitis or signs of persistent obstruction from choledocholithiasis [20, 24-27].

Predicted severe cases and/or those showing clinical deterioration with multi-organ dysfunction require management in the intensive care unit.

Both peripancreatic and pancreatic necrosis usually require treatment when infected, whereas sterile, non-obstructing necrosis can often be managed with a watch-and-wait strategy $[7,12,20]$. It is usual to delay intervention until the necrosis has walled-off, which usually takes approximately 4 weeks from symptom onset, but should not be delayed in the face of a deteriorating clinical scenario. Antibiotic treatment is indicated but only if infection of a necrotic collection is confirmed by fine needle aspiration or clinically suspected, and should be broad-spectrum and able to penetrate into the necrosis.

Left flank retroperitoneal pancreatic necrosectomy, percutaneous catheter and/or endoscopic transgastric drainage, laparoscopic approaches, minimally invasive retroperitoneal pancreatic necrosectomy (MARPN), and the step-up approach of 
Table 2 Definitions of the 2012 Atlanta classification revision

\begin{tabular}{|c|c|}
\hline Definition & Contrast-enhanced computed tomography criteria \\
\hline $\begin{array}{l}\text { Interstitial edematous pancreatitis } \\
\text { Acute inflammation of the pancreatic parenchyma and peripancreatic } \\
\text { tissues, but without recognizable tissue necrosis. }\end{array}$ & Pancreatic parenchyma enhancement by intravenous contrast agent. \\
\hline $\begin{array}{l}\text { Necrotizing pancreatitis } \\
\text { Inflammation associated with pancreatic parenchymal necrosis and/or } \\
\text { peripancreatic necrosis. }\end{array}$ & $\begin{array}{l}\text { Lack of pancreatic parenchymal enhancement by intravenous contrast } \\
\text { agent and/or peripancreatic necrosis. }\end{array}$ \\
\hline $\begin{array}{l}\text { Acute peripancreatic fluid collection (APFC) } \\
\text { Peripancreatic fluid associated with interstitial edematous pancreatitis } \\
\text { with no associated peripancreatic necrosis }<4 \text { weeks after onset of } \\
\text { interstitial edematous pancreatitis and without a pseudocyst. }\end{array}$ & $\begin{array}{l}\text { Interstitial edematous pancreatitis: homogeneous collection with fluid } \\
\text { density, confined by normal peripancreatic fascial planes, without wall } \\
\text { encapsulation, and adjacent to the pancreas without intra-pancreatic } \\
\text { extension. }\end{array}$ \\
\hline $\begin{array}{l}\text { Pancreatic pseudocyst } \\
\text { An encapsulated collection of fluid with a well-defined inflammatory } \\
\text { wall usually outside the pancreas with minimal or no necrosis- } \\
>4 \text { weeks after onset of interstitial edematous pancreatitis. }\end{array}$ & $\begin{array}{l}\text { Well circumscribed, usually round or oval, well-defined wall that is, } \\
\text { completely encapsulated, homogeneous fluid density, no non-liquid } \\
\text { component. }\end{array}$ \\
\hline $\begin{array}{l}\text { Acute necrotic collection (ANC) } \\
\text { A collection containing variable amounts of both fluid and necrosis } \\
\text { associated with necrotizing pancreatitis; the necrosis can involve the } \\
\text { pancreatic parenchyma and/or the peripancreatic tissues. }\end{array}$ & $\begin{array}{l}\text { Acute necrotizing pancreatitis: Heterogeneous and non-liquid density of } \\
\text { varying degrees in different locations (some appear homogeneous early } \\
\text { in their course). No definable wall encapsulating the collection } \\
\text { intra-pancreatic and/or extra-pancreatic. }\end{array}$ \\
\hline $\begin{array}{l}\text { Walled-off necrosis (WON) } \\
\text { A mature, encapsulated collection of pancreatic and/or peripancreatic } \\
\text { necrosis with a well-defined inflammatory wall, }>4 \text { weeks after onset of } \\
\text { necrotizing pancreatitis. }\end{array}$ & $\begin{array}{l}\text { Heterogeneous with liquid and non-liquid density with varying degrees of } \\
\text { loculations (may appear homogeneous initially), well-defined } \\
\text { completely encapsulated wall, intra-pancreatic, and/or extra-pancreatic. }\end{array}$ \\
\hline Severity of acute pancreatitis & Severity criteria \\
\hline Mild acute pancreatitis & $\begin{array}{l}\text { - No organ failure } \\
\text { - No local or systemic complications }\end{array}$ \\
\hline Moderately severe acute pancreatitis & $\begin{array}{l}\text { - Transient organ failure that resolves }<48 \mathrm{~h} \text { and/or } \\
\text { - Local or systemic complications without persistent organ failure }\end{array}$ \\
\hline Severe acute pancreatitis & $\begin{array}{l}\text { - Persistent organ failure that persists }>48 \mathrm{~h} \\
\text { - Single organ failure } \\
\text { - Multiple organ failure }\end{array}$ \\
\hline
\end{tabular}

percutaneous drainage with video-assisted open debridement have all been proposed as alternatives to open pancreatic necrosectomy [13-15, 28-38].

Debridement of infected pancreatic necrosis is the mainstay of treatment when percutaneous drainage fails, which is the case in 25 to $75 \%$ of patients. Open necrosectomy is associated with 34-95\% morbidity and 6-25\% mortality depending on the cohort, expertise, and the disease severity $[14,15,17$, $35,36,39-41]$. In a collected retrospective multicenter study, high-risk cases of infected pancreatic necrosis had a mortality of $53 \%$ using open necrosectomy while less invasive endoscopic methods had a mortality of $38 \%$ [15, 29, 39-41].

\section{Surgical concepts: management of necrosis}

Historically, surgery for necrosis in AP was associated with a very high mortality of up to $50 \%$ or higher [39, 42]. The timing of an intervention is important, with a general rule of thumb suggesting 4 weeks from the start of symptoms to enable walling-off of necrotic tissue, although this may not always be possible because of a deteriorating clinical scenario
$[20,40,43]$. Other crucially important factors for the improvement of morbidity and mortality in the treatment of AP necrosis are advances and paradigm shifts in surgical technique.

\section{Open pancreatic necrosectomy}

The basic principle is the exposure of the necrotic area, usually after transection of the gastro-colic and duodeno-colic ligament, and blunt dissection then debridement of necrotic tissue. Sometimes, it is easier to enter the necrotic cavity as the necrosis invades the transverse colon in the space of Riolan, adjacent to the ligament of Treitz. Subsequently, the necrotic cavity can be managed in various ways as follows [40]:

1. Open Packing: the cavity is packed, and the patient is scheduled for repeat procedures, usually every $48 \mathrm{~h}$, until the necrotic process is resolved; mortality of $12-49 \%$ with infected necrosis in 84-100\% [40, 44].

2. Planned re-laparotomies: after initial necrosectomy and lavage, the patient is scheduled for re-laparotomy; mortality of $17-25 \%$ with infected necrosis in 75-79\% [40, 45]. 
Table 3 IAP/APA evidence-based guidelines for the management of acute pancreatitis

Domain of guidelines

Level of evidence;

level of agreement

A Diagnosis and etiology of AP

12 out of 3 criteria (upper abdominal pain, imaging (CT, EUS, US), elevation of serum amylase/lipase over threefold) are 1B; strong $t$ needed for diagnosis.

2 Etiology should be determined on admission (history, imaging, examination, laboratory tests).

3 For idiopathic AP, EUS should be performed as a next step for microlithiasis detection. If negative, MRCP is recommended. If inconclusive, genetic counseling can be evaluated.

B Prognostication/prediction of severity

4 SIRS is advised to predict severe AP at admission and persistent SIRS at $48 \mathrm{~h}$.

$1 \mathrm{~B}$; strong agreement

$2 \mathrm{C}$; weak

2B; weak

5 A 3-dimension approach (host risk factors, clinical risk stratification, response to initial therapy) is advised to predict outcome of AP.

$\mathrm{C} \quad$ Imaging

6 Indications for initial CT include diagnostic uncertainty, confirmation of severity, failure to respond to conservative treatment. Optimal timing is $72-96 \mathrm{~h}$ after symptom onset.

7 Indications for follow-up CT are lack of clinical improvement, deterioration, planned invasive intervention.

$2 \mathrm{~B}$; strong

CT: thin collimation and slice thickness of $5 \mathrm{~mm}$ or less and 100-150 $\mathrm{ml}(3 \mathrm{ml} / \mathrm{s})$ during pancreatic/portal venous phase are recommended. MRI: axial FS-T2 and FS-T1 before and after $i v$ gadolinium are recommended.

D Fluid therapy

9 Ringer's lactate is recommended.

$1 \mathrm{~B}$; strong

10a Goal-directed therapy with $5-10 \mathrm{ml} / \mathrm{kg} / \mathrm{h}$ should be used initially.

1B; weak

10b Response should be assessed by either (1) heart rate (<120/min), MAP (65-85 mmHg), and urinary output $(>0.5-1 \mathrm{ml} / \mathrm{kg} / \mathrm{h}) ;(2)$ invasive clinical targets of stroke volume variation and intrathoracic blood volume; (3)

$2 \mathrm{~B}$; weak $t$ hematocrit $35-44 \%$.

E Intensive care management

11 Patients fulfilling one or more parameters of the SCCM guidelines or with severe AP (according to Atlanta classification) 1C; strong should be treated in an IC setting.

12 Severe AP and AP requiring surgical/radiological or endoscopic intervention should be treated in a specialist center.

$1 \mathrm{C}$; strong agreement

13 Specialist centers are defined by high-volume, up-to-date IC facilities with the option for organ replacement therapy, daily access to interventional radiology/interventional endoscopy, and surgical expertise with necrotizing AP. Enrollment in prospective audits and into clinical trial whenever possible.

14 Early fluid resuscitation $(<24 \mathrm{~h})$ is associated with decreased rates of persistent SIRS and organ failure.

$1 \mathrm{C}$; strong agreement

Abdominal compartment syndrome (ACS) is defined as intraabdominal pressure $>20 \mathrm{mmHg}$ with new-onset organ failure.

16 Medical treatment for ACS targets (1) hollow viscera volume, (2) intra-/extra-vascular fluid; (3) abdominal wall expansion. Invasive treatment options (when $>25 \mathrm{mmHg}$ and persistent organ failure, multidisciplinary consent) include percutaneous drainage of ascites and surgical decompression. Retroperitoneum and omental bursa should be left intact.

F Preventing infectious complications

17 No routine antibiotic prophylaxis.

18 Selective gut decontamination might be helpful, but further studies are needed.

$1 \mathrm{~B}$; strong

19 Probiotic prophylaxis is not recommended.

2B; weak

G Nutritional support

20 Oral feeding in predicted mild AP can be restarted once pain and inflammatory markers are decreasing.

$1 \mathrm{~B}$; strong

21 Enteral tube feeding as the primary therapy in predicted severe AP.

$2 \mathrm{~B}$; strong

Elemental or polymeric enteral nutrition can be used.

23 Nasojejunal or nasogastric route can be used for enteral nutrition.

24 Parenteral nutrition as second-line therapy when nasojejunal tube is not tolerated and nutritional support is required.

$1 \mathrm{~B}$; strong

2B; strong

$2 \mathrm{~A}$; strong agreement

$2 \mathrm{C}$; strong

$\mathrm{H} \quad$ Biliary tract management

25 ERCP not indicated in mild biliary AP without cholangitis (1A) and probably not indicated in severe biliary AP without Evidence- see text; cholangitis (1B). ERCP probably indicated in biliary AP with common bile duct obstruction (1C). ERCP indicated in strong biliary AP with cholangitis (1B).

26 Urgent ERCP $(<24 \mathrm{~h})$ in patients with acute cholangitis. Evidence regarding optimal timing for ERCP in biliary AP 2C; strong without cholangitis is lacking

27 MRCP and EUS might prevent ERCPs for suspected common bile duct stones. EUS is superior to MRCP in detecting 2C; strong gallstones $<5 \mathrm{~mm}$. MRCP is less invasive and more available. Neither technique clearly superior. 
Table 3 (continued)

Domain of guidelines

Level of evidence;

level of agreement

I Indications for intervention in necrotizing AP

28 Indications include (1) infected necrosis (suspected or documented) with clinical deterioration, preferably when walled-off; (2) ongoing organ failure for several weeks, preferably when necrosis is walled-off.

29 Routine percutaneous FNA to detect bacteria not indicated.

C; strong

$1 \mathrm{C}$; strong a

30 Indications for intervention in sterile necrotizing AP: (1) ongoing gastric outlet obstruction/ biliary obstruction; (2) persistent symptoms; (3) disconnected duct syndrome. Necrosis should be walled-off.

$2 \mathrm{C}$; strong

$\mathrm{J} \quad$ Timing of intervention in necrotizing pancreatitis

31 For infected necrosis, invasive interventions should be delayed until at least 4 weeks after initial presentation to allow 1C; strong walling-off.

32 Surgical necrosectomy should be delayed (for at least 4 weeks, until walled-off) regardless of patient subgroups.

$\mathrm{K} \quad$ Intervention strategies in necrotizing AP

33 Optimal strategy for infected necrotizing AP is either image guided percutaneous-retroperitoneal or endoscopic drainage, 1A; strong followed, if necessary, by endoscopic or surgical necrosectomy.

34 Percutaneous-retroperitoneal or endoscopic drainage should be the first step in the treatment of infected, walled-off AP.

35 Insufficient data to define subgroups of patients who would benefit from different treatments.

$1 \mathrm{~A}$; strong

L Timing of cholecystectomy

36 Mild biliary AP: cholecystectomy during index admission is recommended. Interval cholecystectomy is associated with $1 \mathrm{C}$; strong recurrence.

37 Patients with peripancreatic collections: cholecystectomy should be delayed until collections resolve (or performed after 2C; strong 6 weeks if persisting collections are present).

38 Cholecystectomy recommended in patients after sphincterotomy for biliary AP.

$2 \mathrm{~B}$; strong

3. Closed continuous lavage: two or more large Salem-sump tubes are placed in the necrotic area and the ligaments are re-approximated to create a compartment, followed by high-volume continuous lavage immediately from the end of surgery; mortality of $12-49 \%$ with infected necrosis in $39-100 \%$ [40, 46, 47].

4. Closed packing: packing of the area is combined with insertion of Penrose drains and closed-suction drains; mortality of $6 \%$ reported in one series from the Massachusetts General Hospital in Boston of 64 patients with infected necrosis in only $56 \%$ [48].

Closed continuous lavage and closed packing are naturally associated with fewer re-interventions (no scheduled relaparotomy) and fewer complications such as gastrointestinal or colonic fistulas and incisional hernias [40, 46-48]. In a subsequent series from the Massachusetts General Hospital of 167 patients, the mortality was $20.3 \%$ in patients receiving open debridement and closed packing in the first 28 days after symptom onset but only $5.1 \%$ with debridement and closed packing after 28 days [49]. A retrospective study from Finland of open necrosectomy in 109 had a 90 -day mortality of $22.9 \%$ but with the subgroup being operated on after 28 days $(N=91)$, this was only $10.6 \%$ [50]. Longitudinal data from the Liverpool Pancreas Unit demonstrates a significant improvement in terms of mortality and overall complications for open pancreatic necrosectomy and minimally invasive approaches when comparing singlecenter data from 1997-2008 to 2008-2013 [14, 15].
In summary, open pancreatic necrosectomy can be a viable treatment option in selected patients. It remains the method of choice when other, less invasive options fail. However, other approaches have gained widespread acceptance over the last two decades and retroperitoneal access procedures represent the new standard of care that is going to be discussed below.

\section{Minimal access retroperitoneal pancreatic necrosectomy}

The advent of high-resolution contrast-enhanced computed tomography (CT) and sophisticated optical and surgical instrumentation enabled clinicians of the late twentieth century to assess different minimally invasive routes to pancreatic and peripancreatic necroses in AP patients [51-53].

Retroperitoneoscopic access emerged as one of the most promising techniques. Intraabdominal dissemination of infectious necrotic tissue and subsequent septic shock are avoided/ minimized utilizing this extraperitoneal approach. Pioneered in Glasgow and Liverpool MARPN or minimal access retroperitoneal pancreatic necrosectomy (sometimes also referred to as minimally invasive retroperitoneal pancreatic necrosectomy $=$ MIRPN) has influenced the development on minimally invasive approaches in centers across the world $[14,15,29,30]$. MARPN is also referred to as "skunking" as the necrotic material being removed initially usually has a strong offensive odor. 
Technique of minimal access retroperitoneal pancreatic necrosectomy (Fig. 2) First, a 12-French catheter over a flexible guidewire is placed into the necrotic area under local anesthetic by a specialist interventional radiologist under CT guidance using a standard Seldinger technique. This follows a left flank line of retroperitoneal access between the spleen, the splenic flexure of the colon, and the left kidney [30]. The approach from the right flank is usually not possible because the duodenum and the inferior vena cava block the line of access into the head of the pancreas. The patient may then be transferred back to the intensive care unit or regular ward to await theater or go straight to the operating room. The patient is placed in a supine position with the left (or right) flank being elevated with a sandbag for better access. The patient may be given a light anesthetic, or alternatively the whole procedure can be conducted without any sedation or analgesia except for local anesthetic around the guidewire skin entry point to enable an incision in order to widen the track access site. The index case was an elderly patient with aortic stenosis and cardiovascular disease, undertaken only with local skin anesthetic who watched the whole procedure on the nephroscope video monitor.

The catheter is then removed leaving the guidewire in situ under radiologic control by a $\mathrm{C}$-arm. After confirmation of correct guidewire placement and incision of the skin, it is replaced by a plastic sheath, and the tract is serially dilated using a renal dilatation set. Once a 30-French tract has been established, a plastic sheath is left in place to prevent collapsing, and a rigid nephroscope with a video screen connection is used to visualize the necrosis. Continuous irrigation with saline-solution is essential to facilitate visualization of the cavity. Biopsy forceps are used to remove the black and/or gray necrotic tissue, which is readily distinguished from normal tissue which is pink or white.

An irrigation drainage system for continuous lavage on the ward is positioned under radiologic control. A bespoke drainage system is used comprising a pediatric 12-French nasogastric tube transfixed to the proximal tip of a large 28-French semi-rigid chest drain with additional holes cut out proximally and both tubes then suture-transfixed to the skin. The chest drain is connected to a large collecting bag (such as a urine bag) that can measure the fluid output and be emptied through a separate outlet tube. The rate of lavage should start at $3 \mathrm{~L} /$ $24 \mathrm{~h}$ using normal saline and be commenced in the operating room to ensure unobstructed in-flow of saline and a steady outflow of lavage effluent. The inflow and outflow should be regularly recorded to ensure that the volumes are more or less equal over a 24 -h period.

The main objective of the first procedure is to decompress the necrotic cavity which is normally under tension and send the pus and other infected tissues for culture and antibiotic sensitivities.

Several procedures are usually needed for a successful debridement and at the initial procedure, the surgeon should not aim to remove every necrotic piece that is visualized. For subsequent procedures, the plastic sheath and the nephroscope are reintroduced under visual control and no radiologic imaging is necessary except for the placement of the lavage drainage system. Again, these repeat procedures may not require a general anesthetic. The necrotic cavity will gradually collapse, and the necrotic areas will be replaced by healthy pink granulation tissue. Major vessels including the splenic and superior mesenteric arteries and superior mesenteric vein and the inferior vena cava may be seen. The steady collapse of the cavity can be radiologically monitored using soluble contrast injected into the cavity via the lavage system (a "tubogram") and also by contrast-enhanced CT. As the patient steadily improves, the rate of lavage can be reduced but may need to be increased again if there is clinical deterioration. The progress of the patient can also be followed using sequential serum levels of CRP. Rising levels of CRP indicate the need for repeat skunking and/or new collections developing. Once the CRP falls to around $50 \mathrm{mg} / \mathrm{L}$, further interventions are unlikely and when $30 \mathrm{mg} / \mathrm{L}$ or less the lavage may be stopped. At this stage, the chest drain tube is cut and a colostomy bag is placed around this to collect the effluent.

Most patients will be discharged home with a drainage bag in situ and followed up weekly. If the drain becomes blocked with thick debris and/or pus, it can be flushed with a small volume of normal saline. The drainage tube is shortened by $2-$ $5 \mathrm{~cm}$ every week or so to enable the sinus tract to granulate towards the skin. With $10-15 \mathrm{~cm}$ remaining, the chest drain is downsized to a tube with a smaller diameter such as an 18French nasogastric tube cut to size. It is important to allow the tract to fully granulate before the skin closes over the tract; otherwise, this will cause a subcutaneous abscess.

MARPN was initially limited to necroses in the pancreatic tail and body. Over time, indications have been expanded to necroses in the paracolic gutters usually by additional access tracts aiming caudally from the left and/or right flanks. Additional drainage tubes may be required for pelvic collections and transgastric or transduodenal routes for endoscopic drainage of the head of the pancreas if left-sided access is insufficient for complete debridement. A single multipurpose laparoscopic port inserted extra-peritoneally may facilitate access to paracolic necrotic collections, using a zero-degree nephroscope, and an articulated grasper and continuous irrigation/drainage, but of course not entering the peritoneal cavity. These combined procedures are classified as complex MARPNs [15]. This means that, in patients where debridement is indicated, the majority of cases can be treated via retroperitoneoscopic approaches without entering the peritoneal cavity and avoiding large abdominal incisions.

Results of minimal access retroperitoneal pancreatic necrosectomy In the original series from Glasgow, there were two $(14.3 \%)$ deaths from 14 patients with infected pancreatic 

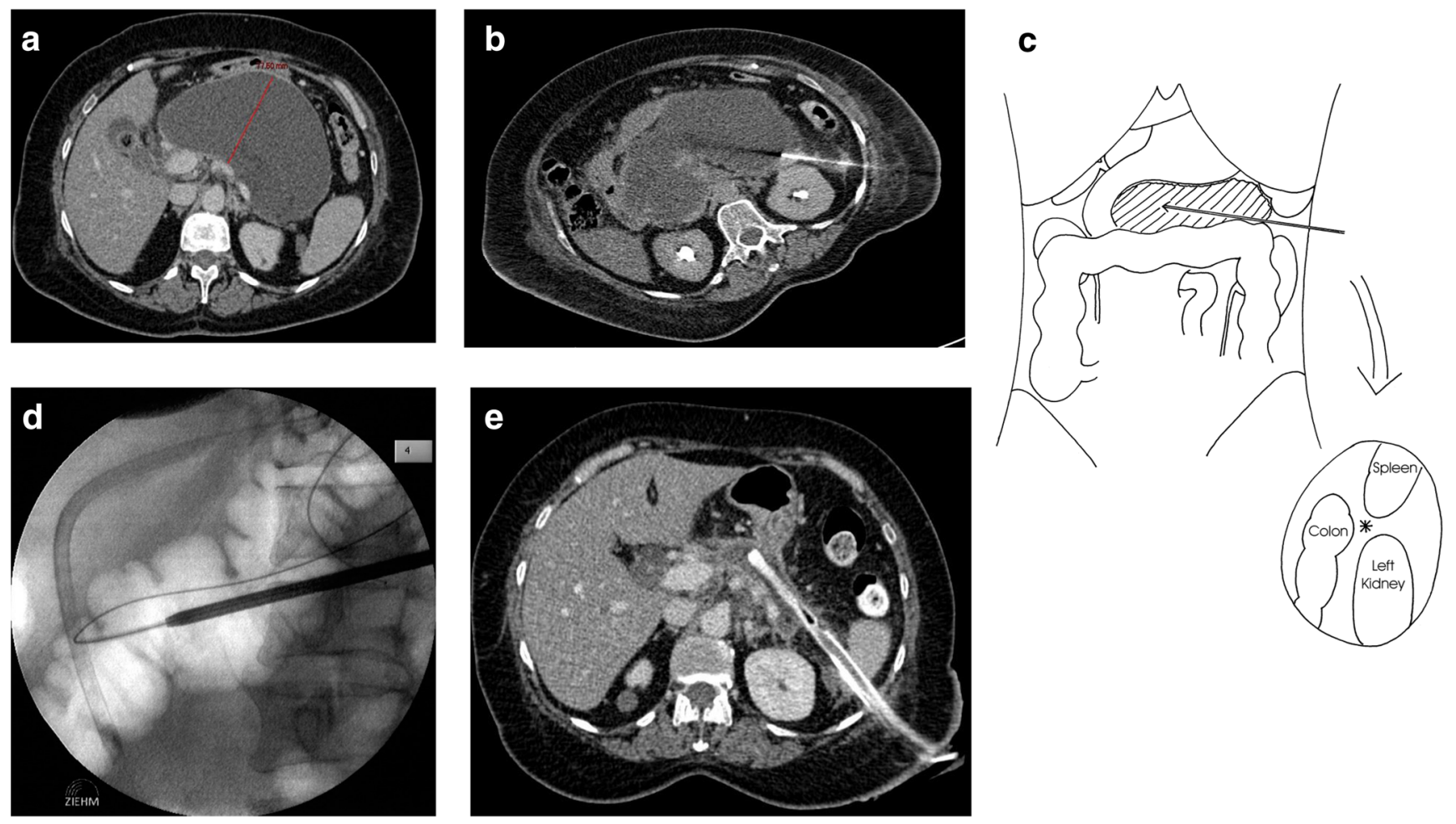

Fig. 2 The serial treatment of necrotizing pancreatitis by MARPN (a). In the radiology department, the guidewire is inserted into the center of the necrotic mass, taking a line between the lower pole of the spleen, the splenic flexure of the colon, and the upper pole of the left kidney (b, c). Then in the operating room, the surgeon dilates the guidewire track using increasing diameter nephrectomy dilators, under X-ray control using the vertebral column and the position of a nasogastric tube as a reference point (d). Following multiple skunk procedures using a straight rigid nephroscope, the necrosis has largely been cleared and the necrotic cavity has collapsed around the 28-French chest drain (e); the tract will heal by granulation tissue on steady withdrawal then downsizing of the drain over several weeks as an outpatient necrosis treated by MARPN [29]. In a small series of 18 patients with infected pancreatic necrosis from Beijing, all were successfully treated by MARPN without morbidity or mortality [54]. In the series of 394 patients with pancreatic necrosis (77.7\% infected) from Liverpool, the mortality was lower in MARPN-treated patients (15.3-19\%) compared with that treated with open pancreatic necrosectomy (23.3-38\%) [14, 25]. The rate of post-operative multi-organ failure is lower after MARPN (20.4-31\% versus 35-56\% respectively), and there are fewer post-operative complications (55.0-63.5\% versus $81.0-81.7 \%$ ) $[14,15]$.

\section{Left flank necrosectomy and video-assisted retroperitoneal debridement}

In 1989, Fagniez and colleagues from Créteil, France, described a direct retroperitoneal approach for necrosectomy in 40 patients with severe acute pancreatitis, all but one with infected necrosis, and 18 had failed pancreatic surgery elsewhere [28]. The approach was with a left lateral incision, just anterior to the 12 th rib, allowing direct access to the pancreas and a complete manual exploration of the gland and peripancreatic spaces. Thirteen patients $(32.5 \%)$ died, although only four patients $(18.2 \%)$ out of the 22 operated on primarily in Créteil. Twenty patients (50\%) developed a local complication including major hemorrhage in eight and eleven with colonic fistula and/or necrosis, and one with a gastric fistula. Respiratory failure developed in ten patients and another seven patients developed multi-organ failure [28].

Van Santvoort et al. adopted video-assisted retroperitoneal debridement (VARD) beginning with a left flank sub-costal incision to directly remove necrosis followed by a laparoscope to access deeper lying necrosis and then using continuous lavage [55]. They described as "a hybrid between pure endoscopic retroperitoneal necrosectomy and the open $(20 \mathrm{~cm}$ incision) translumbar approach, described by Fagniez et al. in 1989" [55]. Unfortunately, it is not possible to obtain any clear outcome data on the VARD procedure as it is contained within the "step-up approach" that provides combined outcome data with prior percutaneous drainage $[31,34]$.

In the PANTER multi-center trial from the Netherlands, 88 patients with necrotizing pancreatitis were randomly assigned to undergo up-front open necrosectomy with continuous lavage or a step-up approach combining initial percutaneous drainage and if there was no clinical improvement, then necrosectomy by VARD [31]. The primary endpoint was a composite of major complications which included new-onset multiple organ failure or multiple systemic complications, 
perforation of a visceral organ or enterocutaneous fistula, or bleeding, or death. The primary endpoint occurred in 31 $(69 \%)$ of 45 patients assigned to open necrosectomy and in $17(40 \%)$ of 43 patients assigned to the step-up approach. In the step-up approach group, 17 patients had percutaneous drainage only but with two $(11.8 \%)$ deaths. There were six $(23.1 \%)$ deaths in the remaining 26 patients who had VARD, compared with seven $(15.6 \%)$ deaths in the 45 patients that had open necrosectomy [31]. Follow-up showed that in the step-up group, patients had fewer incisional hernias and less exocrine insufficiency (not surprisingly but there were no differences between the groups in terms of recurrent acute or chronic pancreatitis, endoscopic or surgical interventions pancreatic, quality of life, or costs) [36].

\section{Endoscopic transgastric necrosectomy}

The Dutch Pancreatitis Study Group subsequently undertook a multicenter study in which patients were randomly assigned to one of two step-up groups, the endoscopic approach $(N=$ 51) consisting of endoscopic ultrasound-guided transluminal drainage followed, if necessary, by endoscopic necrosectomy and the surgical approach consisting of percutaneous catheter drainage followed, if necessary, by VARD $(N=47)$ [34]. Endoscopic necrosectomy was undertaken in 29 (56.8\%) patients randomized to the endoscopy group and VARD was undertaken in $23(51.1 \%)$ patients in the surgery group [34]. There were nine (18\%) deaths in the endoscopy group and six $(13 \%)$ patients in the surgery group but we do not know how many deaths occurred before the endoscopic intervention or VARD; major complications or death occurred in $22(43 \%)$ and $21(45 \%)$ patients, respectively [34].

A single-center study from Florida Hospital in Orlando, USA, randomized 32 of 66 patients with pancreatic necrosis to minimally invasive surgery, either laparoscopic cystogastrostomy or VARD depending on location of collection, and 34 patients to an endoscopic step-up approach comprising transluminal drainage with or without necrosectomy. The primary endpoint was a composite of major complications of new-onset multiple organ failure, new-onset systemic dysfunction, enteral or pancreatic-cutaneous fistula, bleeding, and perforation of a visceral organ or death during 6 months of follow-up. Death occurred in two $(6.3 \%)$ patients in the surgery group and in three $(8.8 \%)$ patients in the endoscopy group; the primary endpoint occurred in four $(11.8 \%)$ patients who received endoscopic procedure and in $13(40.6 \%)$ patients who had minimally invasive surgery [56].

\section{Comparison of outcomes of different techniques}

Comparison of the different techniques is not straightforward as:
1. Different techniques are used sequentially on the same patient thereby altering the characteristics of the outcomes for each type of technique, thus introducing a selection bias [57];

2. Description of key characteristic features of the pancreatitis may not be included such as the presence or absence of pancreatic necrosis, extent of pancreatic necrosis, transient or persistent organ failure, and pre-operative and post-operative intensive therapy unit (ITU) requirement;

3. Details of infected or sterile pancreatic necrosis before intervention are missing, as once intervention takes place, infection is almost invariably acquired, so falsely reported as being infected necrosis;

4. Selective bias with late referrals of patients: for example, in the three-center (Calgary, Stanford, and Indiana) retrospective study on surgical transgastric necrosectomy for necrotizing pancreatitis as a single-stage procedure for walled-off pancreatic necrosis, the median delay from symptom onset to surgical treatment was 53,60 , and 71 days, respectively, leaving only the relatively lowrisk survivors to have the surgery [37];

5. Lack of a clear distinction between acute peripancreatic fluid collections (which do not need treatment), pancreatic pseudocysts (which usually resolve without treatment), pancreatic necrosis, acute necrotic collection, and walled of necrosis, all with different outcomes;

6. Grouping various minimized techniques together, such as MARPN, VARD, and endoscopic transgastric necrosectomy (ETN), when they are probably not comparable in terms of outcomes $[35,58]$;

7. Use of composite endpoints where significant differences might be seen due to potentially biased observations such as pancreatic enzyme replacement therapy, or pancreatic fistula (which by definition always occurs with a percutaneous approach), while unbiased events such as death (when there may be no significant difference) assume a secondary significance [56].

Considering these reservations, data for various techniques are shown in Table 4 for comparison. Although VARD has been promoted, the data on how effective it is are rather small compared with MARPN $[15,31]$. A recent series of 179 consecutive patients with necrotizing pancreatitis from the Massachusetts General Hospital, Boston, USA, revealed a 90day mortality rate of only 2/91 (2.2\%) in patients treated by a variety of minimally invasive techniques (including ETN, STE, and VARD) compared with $9 / 88(10.2 \%)$ in patients treated by open necrosectomy [58]. The International Association of Pancreatology/American Pancreatic Association guidelines recommend either a conventional or endoscopic step-up approach as the initial treatment strategy of choice in patients with infected necrosis or persistent organ failure and necrosis [20]. One advantage of this approach is that more invasive interventions 
of incorrectly diagnosed necrotic collections - that are actually acute peripancreatic fluid collections (that do not need treatment) or pseudocysts (that mostly resolve) - are avoided. One disadvantage is that initial drainage only leads to partial resolution of a necrotic collection that subsequently complicates minimal access approaches, forcing an open necrosectomy that would have been otherwise avoidable.

The American Gastroenterological Association (AGA) Clinical Practice Update on the management of pancreatic necrosis recommends that the use of direct endoscopic necrosectomy should be reserved for those patients with limited necrosis who do not adequately respond to endoscopic transmural drainage using large-bore, self-expanding metal stents/lumen-apposing metal stents alone or plastic stents combined with irrigation [59]. The AGA also recommends that minimally invasive operative approaches to the debridement of acute necrotizing pancreatitis are to be preferred to open surgical necrosectomy whenever possible [59].

\section{Other complications and their surgical management}

\section{Colonic and enteric fistula}

Enteric and especially colonic necrosis, ischemia, and hemorrhage in the context of severe AP are usually caused by the spread of pancreatic enzymes and pancreatic/peripancreatic necrosis. If suspected, colonic resection is essential $[15,60]$. Colonic fistulas, which can appear in 17-19\% of patients, are associated with increased mortality [61]. This complication can be managed without surgery utilizing percutaneous drainage in around $47 \%$ of cases. In a large series including 132 patients with colonic fistula, mortality in patients requiring surgical intervention for colonic fistula was higher (37\%) compared with the group receiving percutaneous drainage (19\%) [61].

\section{Hemorrhage}

Pancreatic fistula and necrosis can erode blood vessels involved in the collection causing major bleeding and occurs in $15-18 \%$ of cases and pseudo-aneurysm in around $4 \%$ [15]. With open pancreatic necrosectomy, the mortality is very high. In a collected series of 44 cases reported in 2003, the overall mortality rate was $34.1 \%$ [62]. The splenic artery, portal vein, spleen, and unspecified peripancreatic vessels were the most commonly involved sources of bleeding, with associated mortality rates of $33.3 \%, 50.0 \%, 30 \%$, and $28.5 \%$, respectively [62]. Massive hemorrhage was more frequently associated with severe necrosis, with a mortality rate of $37.9 \%$ [62]. Earlier on in the Liverpool series, the mortality rate was $70 \%$ when attempted treatment for massive hemorrhage was straight to open laparotomy and packing [63]. Subsequently, for bleeding in patients who had MARPN, tamponade of the bleeding was introduced simply by stopping the continuous irrigation and clamping the chest drain with arterial forceps; in most cases, the bleeding would be controlled without the need for further intervention. For open necrosectomy, the standard procedure for bleeding is emergency angiography and embolization, and only if this is not successful should there be a laparotomy followed by packing to control the bleeding. Using this approach, the mortality was only $16 \%$ from bleeding in the Liverpool series [14].

\section{Disconnected main pancreatic duct}

Disconnected main pancreatic duct (DPD) is defined as a discontinuity of the main pancreatic duct (MPD) and is a feature of severe necrotizing pancreatitis with central pancreatic necrosis first described in 1993 [64]. An external pancreatic fistula will therefore be usually expected using MARPN/ VARD/percutaneous drainage for severe necrotizing pancreatitis. It can be managed as an outpatient procedure by gradual shortening of external drain then downsizing using a smaller French diameter nasogastric tube cut to size and aggressive endoscopic or surgical interventions are not usually necessary [65]. Late recurrence leading to a drain tract pseudocyst can occasionally occur due to a distal structure in the neck or head of the pancreas and is then best managed by Roux-en-Y pseudocyst-enterostomy [65].

\section{Abdominal compartment syndrome}

Severe AP is accompanied by drastic compartment fluid shifts especially into the interstitial spaces leading to abdominal compartment syndrome. Although laparostomy has been suggested as a means of treatment, there is no quality evidence to support this and may well be deleterious to the condition of the patient.

\section{Timing of cholecystectomy}

Cholecystectomy is recommended for patients with gallstone associated pancreatitis in order to prevent further attacks and should be undertaken at the index admission is recommended for mild biliary pancreatitis $[20,66]$. For patients with peripancreatic collections, however, cholecystectomy should be delayed until the collections have resolved or until after 6 weeks as there is a higher risk for sepsis $[20,67]$.

\section{Summary and outlook}

Severe AP still is a life-threatening condition requiring a multidisciplinary approach. An accurate diagnosis should be made a soon as possible, and initiating resuscitation with large volume intravenous fluids and oxygen by mask. If there is any doubt of the diagnosis, then an urgent contrast-enhanced CT scan should be undertaken. If severe disease is predicted using 


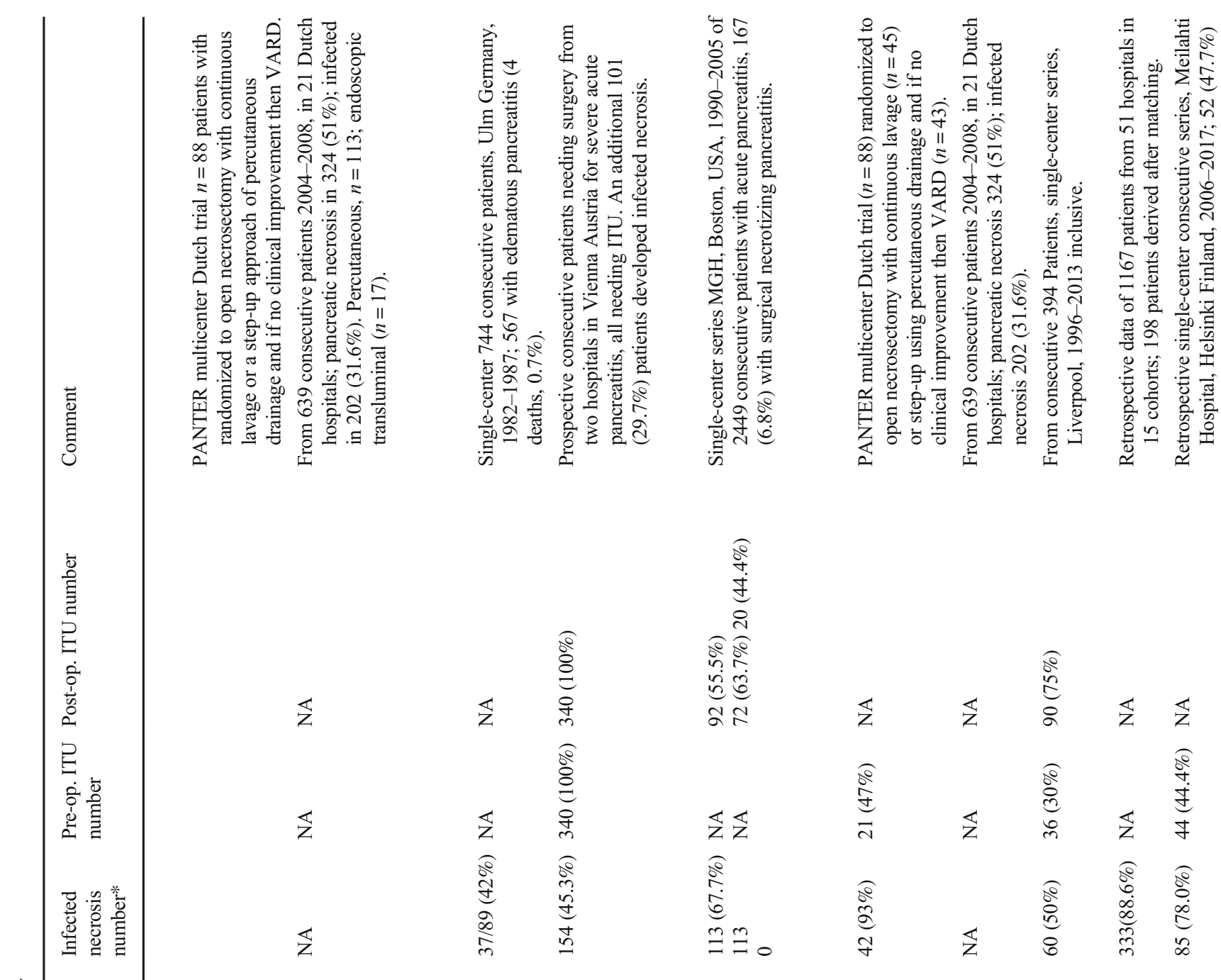




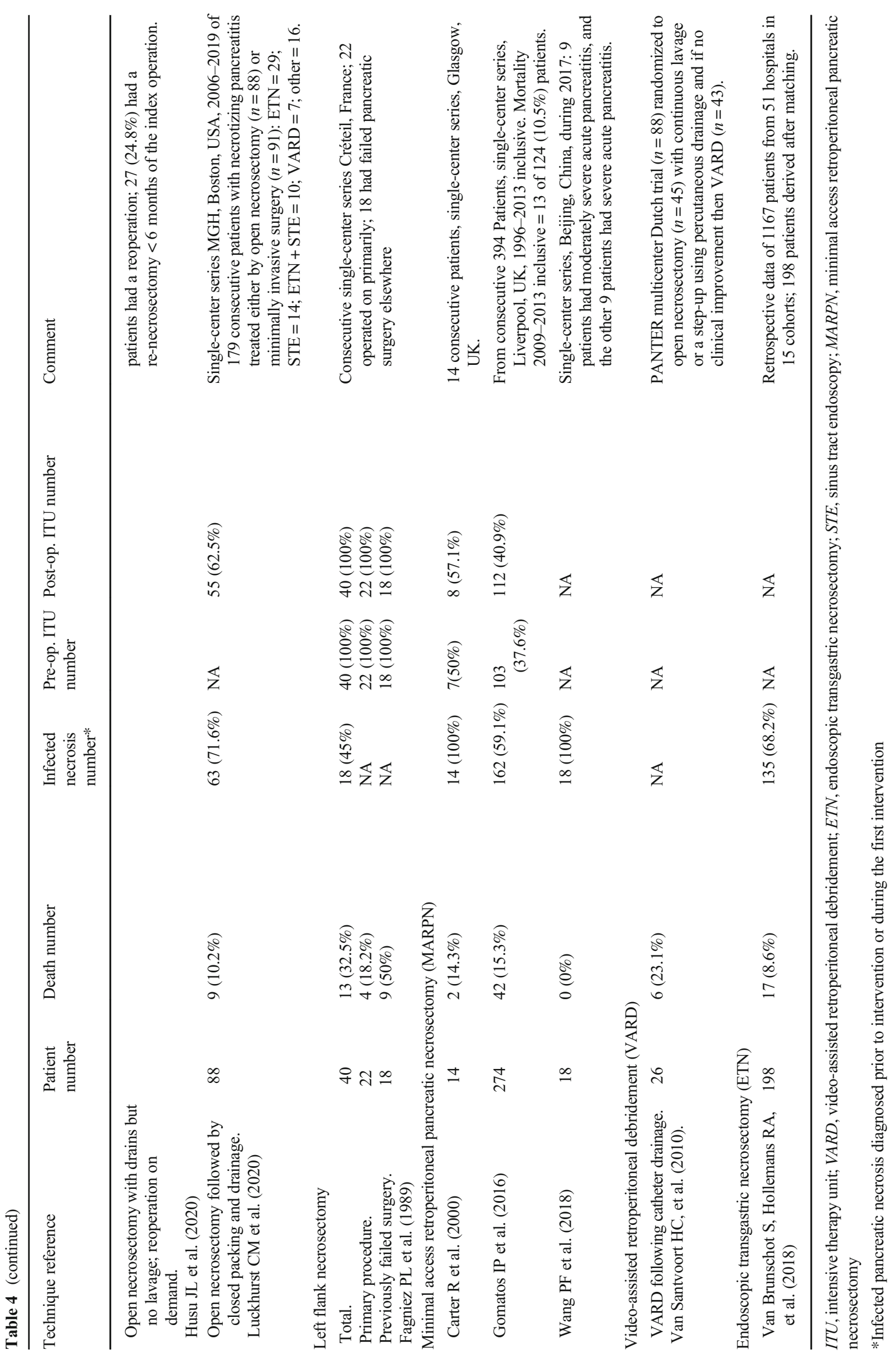


clinical assessment and serum CRP $>150 \mathrm{mg} / \mathrm{L}$, the patient will require intensive monitoring. Most deaths within the first week or so are due to multi-organ failure so severe cases will require management on the intensive therapy unit. During the second phase of the disease, death is due to local complications arising from the pancreatic inflammation. Accurate identification of these local complications is required to determine the correct form of treatment. Acute peripancreatic fluid collections are common, not requiring any treatment. Most pancreatic pseudocysts also largely resolve on conservative management, not needing intervention. Necrotizing pancreatitis causing acute necrotic collections and later walled-off necrosis will require treatment if symptomatic or infected. Initial endoscopic transgastric or percutaneous drainage will resolve less serious collections but necrosectomy using minimally invasive approaches will be needed for more serious collections and usually require a combination of techniques for larger extensive collections. To prevent recurrent attacks of AP, then causative factors need to be removed where possible. Future progress needs to be focused on better management of multiorgan failure in the first phase and more effective minimally invasive techniques for removal of necrosis.

Authors' contributions MH and JPN drafted the manuscript and created the tables and figures. All authors revised the manuscript critically for important intellectual content and approved the version to be published.

Funding Open Access funding provided by Projekt DEAL.

\section{Compliance with ethical standards}

Conflict of interest Dr. Heckler has nothing to disclose; Prof. Dr. med. Hackert has nothing to disclose; Dr. Hu has nothing to disclose; Dr. Halloran reports grants from Cancer Research UK, grants from Pancreatic Cancer UK, grants from the NIHR-RfPb, and grants from the Royal College of Surgeons of England, all outside the submitted work; Prof. Dr. med. Büchler reports Board Membership of B. Braun Melsungen $\mathrm{GmbH}$, outside the submitted work; Prof. Dr. med. Neoptolemos reports grants from the Heidelberger Stiftung Chirurgie, grants from NUCANA, and grants from the Stiftung Deutsche Krebshilfe, all outside the submitted work; .

Ethical approval This article does not contain any studies with human participants performed by any of the authors, outside of previously published work.

Open Access This article is licensed under a Creative Commons Attribution 4.0 International License, which permits use, sharing, adaptation, distribution and reproduction in any medium or format, as long as you give appropriate credit to the original author(s) and the source, provide a link to the Creative Commons licence, and indicate if changes were made. The images or other third party material in this article are included in the article's Creative Commons licence, unless indicated otherwise in a credit line to the material. If material is not included in the article's Creative Commons licence and your intended use is not permitted by statutory regulation or exceeds the permitted use, you will need to obtain permission directly from the copyright holder. To view a copy of this licence, visit http://creativecommons.org/licenses/by/4.0/.

\section{References}

1. Whitcomb DC (2019) Pancreatitis: TIGAR-O version 2 risk/etiology checklist with topic reviews, updates, and use primers. Clin Transl Gastroenterol 10(6):e00027. https://doi.org/10.14309/ ctg.0000000000000027

2. Yadav D, Lowenfels AB (2013) The epidemiology of pancreatitis and pancreatic cancer. Gastroenterology. 144(6):1252-1261

3. Gryshchenko O, Gerasimenko JV, Peng S, Gerasimenko OV, Petersen $\mathrm{OH}$ (2018) Calcium signalling in the acinar environment of the exocrine pancreas: physiology and pathophysiology. J Physiol 596(14):2663-2678

4. Romac JMJ, Shahid RA, Swain SM, Vigna SR, Liddle RA (2018) Piezo1 is a mechanically activated ion channel and mediates pressure induced pancreatitis. Nat Commun 9(1):1715. Published 2018 Apr 30. https://doi.org/10.1038/s41467-018-04194-9

5. Pallagi P, Madácsy T, Varga Á, Maléth J (2020) Intracellular Ca2+ signalling in the pathogenesis of acute pancreatitis: recent advances and translational perspectives. Int J Mol Sci 21(11):1-18

6. Johnson CD, Kingsnorth AN, Imrie CW, McMahon MJ, Neoptolemos JP, McKay C et al (2001) Double blind, randomised, placebo controlled study of a platelet activating factor antagonist, lexipafant, in the treatment and prevention of organ failure in predicted severe acute pancreatitis. Gut. 48(1):62-69

7. Raraty MGT, Connor S, Criddle DN, Sutton R, Neoptolemos JP (2004) Acute pancreatitis and organ failure: pathophysiology, natural history, and management strategies. Curr Gastroenterol Rep 6(2):99-103

8. Petrov MS, Yadav D (2019) Global epidemiology and holistic prevention of pancreatitis. Nat Rev Gastroenterol Hepatol 16(3):175184

9. Roberts SE, Morrison-Rees S, John A, Williams JG, Brown TH, Samuel DG (2017) The incidence and aetiology of acute pancreatitis across Europe. Pancreatology. 17(2):155-165

10. Hamada S, Masamune A, Kikuta K, Hirota M, Tsuji I, Shimosegawa T (2014) Nationwide epidemiological survey of acute pancreatitis in Japan. Pancreas. 43(8):1244-1248

11. Fagenholz PJ, Fernández-Del Castillo C, Harris NS, Pelletier AJ, Camargo CA (2007) Direct medical costs of acute pancreatitis hospitalizations in the United States. Pancreas. 35(4):302-307

12. Banks PA, Bollen TL, Dervenis C, Gooszen HG, Johnson CD, Sarr MG et al (2013) Classification of acute pancreatitis - 2012: revision of the Atlanta classification and definitions by international consensus. Gut. 62(1):102-111

13. Van DIjk SM, Hallensleben NDL, Van Santvoort HC, Fockens P, Van Goor H, Bruno MJ et al (2017) Acute pancreatitis: recent advances through randomised trials. Gut. 66(11):2024-2032

14. Raraty MGT, Halloran CM, Dodd S, Ghaneh P, Connor S, Evans J et al (2010) Minimal access retroperitoneal pancreatic necrosectomy: improvement in morbidity and mortality with a less invasive approach. Ann Surg 251(5):787-793

15. Gomatos IP, Halloran CM, Ghaneh P, Raraty MGT, Polydoros F, Evans JC et al (2016) Outcomes from minimal access retroperitoneal and open pancreatic necrosectomy in 394 patients with necrotizing pancreatitis. Ann Surg 263(5):992-1001

16. Beger HG, Bittner R, Block S, Büchler M (1986) Bacterial contamination of pancreatic necrosis. A prospective clinical study. Gastroenterology 91(2):433-438

17. Connor S, Alexakis N, Neal T, Raraty M, Ghaneh P, Evans J et al (2004) Fungal infection but not type of bacterial infection is associated with a high mortality in primary and secondary infected pancreatic necrosis. Dig Surg 21(4):297-304 
18. Werge M, Novovic S, Schmidt PN, Gluud LL (2016) Infection increases mortality in necrotizing pancreatitis: a systematic review and meta-analysis. Pancreatology. 16(5):698-707

19. Dellinger EP, Forsmark CE, Layer P, Lévy P, Maraví-Poma E, Petrov MS et al (2012) Determinant-based classification of acute pancreatitis severity: an international multidisciplinary consultation. Ann Surg 256(6):875-880

20. (2013) IAP/APA evidence-based guidelines for the management of acute pancreatitis. Pancreatology 13(4 SUPPL. 2):e1-e15

21. Marshall JC, Cook DJ, Christou NV, Bernard GR, Sprung CL, Sibbald WJ (1995) Multiple organ dysfunction score: a reliable descriptor of a complex clinical outcome. Crit Care Med 23(10): $1638-1652$

22. Neoptolemos JP, Kemppainen EA, Mayer JM, Fitzpatrick JM, Raraty MGT, Slavin J et al (2000) Early prediction of severity in acute pancreatitis by urinary trypsinogen activation peptide: a multicentre study. Lancet. 355(9219):1955-1960

23. Gomatos IP, Xiaodong X, Ghaneh P, Halloran C, Raraty M, Lane B et al (2014) Prognostic markers in acute pancreatitis. Expert Rev Mol Diagn 14(3):333-346

24. Neoptolemos JP, London NJ, James D, Carr-Locke DL, Bailey IA, Fossard DP (1988) Controlled trial of urgent endoscopic retrograde cholangiopancreatography and endoscopic sphincterotomy versus conservative treatment for acute pancreatitis due to gallstones. Lancet 332(8618):979-983

25. Fan ST, Lai E, Mok F, Lo CM, Zheng, Sen S, Wong J (1993) Early treatment of acute biliary pancreatitis by endoscopic papillotomy. $\mathrm{N}$ Engl J Med 328(4):228-232

26. Van Santvoort HC, Besselink MG, De Vries AC, Boermeester MA, Fischer K, Bollen TL et al (2009) Early endoscopic retrograde cholangiopancreatography in predicted severe acute biliary pancreatitis: a prospective multicenter study. Ann Surg 250(1):68-75

27. Schepers NJ, Hallensleben NDL, Besselink MG, Anten MGF, Bollen TL, da Costa DW et al (2020) Urgent endoscopic retrograde cholangiopancreatography with sphincterotomy versus conservative treatment in predicted severe acute gallstone pancreatitis (APEC): a multicentre randomised controlled trial. Lancet 396(10245):167-176

28. Fagniez P-L, Rotman N, Kracht M (1989) Direct retroperitoneal approach to necrosis in severe acute pancreatitis. Br J Surg 76(3): 264-267

29. Carter CR, McKay CJ, Imrie CW (2000) Percutaneous necrosectomy and sinus tract endoscopy in the management of infected pancreatic necrosis: an initial experience. Ann Surg 232(2): $175-180$

30. Connor S, Ghaneh P, Raraty M, Sutton R, Rosso E, Garvey CJ et al (2003) Minimally invasive retroperitoneal pancreatic necrosectomy. Dig Surg 20(4):270-277

31. Van Santvoort HC, Besselink MG, Bakker OJ, Hofker HS, Boermeester MA, Dejong CH et al (2010) A step-up approach or open necrosectomy for necrotizing pancreatitis. N Engl J Med 362(16):1491-1502

32. Rische S, Riecken B, Degenkolb J, Kayser T, Caca K (2013) Transmural endoscopic necrosectomy of infected pancreatic necroses and drainage of infected pseudocysts: a tailored approach. Scand J Gastroenterol 48(2):231-240

33. Kumar N, Conwell DL, Thompson CC (2014) Direct endoscopic necrosectomy versus step-up approach for walled-off pancreatic necrosis comparison of clinical outcome and health care utilization. Pancreas. 43(8): 1334-1339

34. van Brunschot $\mathrm{S}$, van Grinsven J, van Santvoort HC, Bakker OJ, Besselink MG, Boermeester MA et al (2018) Endoscopic or surgical step-up approach for infected necrotising pancreatitis: a multicentre randomised trial. Lancet 391(10115):51-58

35. van Brunschot $\mathrm{S}$, Hollemans RA, Bakker OJ, Besselink MG, Baron TH, Beger HG et al (2018) Minimally invasive and endoscopic versus open necrosectomy for necrotising pancreatitis: a pooled analysis of individual data for 1980 patients. Gut. 67(4):697-706

36. Hollemans RA, Bakker OJ, Boermeester MA, Bollen TL, Bosscha K, Bruno MJ et al (2019) Superiority of step-up approach vs open necrosectomy in long-term follow-up of patients with necrotizing pancreatitis. Gastroenterology. 156(4):1016-1026

37. Driedger M, Zyromski NJ, Visser BC, Jester A, Sutherland FR, Nakeeb A et al (2020) Surgical transgastric necrosectomy for necrotizing pancreatitis: a single-stage procedure for walled-off pancreatic necrosis. Ann Surg 271(1):163-168

38. Saunders R, Ramesh J, Cicconi S, Evans J, Yip VS, Raraty M et al (2019) A systematic review and meta-analysis of metal versus plastic stents for drainage of pancreatic fluid collections: metal stents are advantageous. Surg Endosc 33(5):1412-1425

39. Götzinger P, Sautner T, Kriwanek S, Beckerhinn P, Barlan M, Armbruster $C$ et al (2002) Surgical treatment for severe acute pancreatitis: extent and surgical control of necrosis determine outcome. World J Surg 26(4):474-478

40. Werner J, Feuerbach S, Uhl W, Büchler MW (2005) Management of acute pancreatitis: from surgery to interventional intensive care. Gut. 54(3):426-436

41. Babu RY, Gupta R, Kang M, Bhasin DK, Rana SS, Singh R (2013) Predictors of surgery in patients with severe acute pancreatitis managed by the step-up approach. Ann Surg 257(4):737-750

42. Mier J, Luque-De León E, Castillo A, Robledo F, Blanco R (1997) Early versus late necrosectomy in severe necrotizing pancreatitis. Am J Surg 173(2):71-75

43. van Grinsven J, van Brunschot S, Bakker OJ, Bollen TL, Boermeester MA, Bruno MJ et al (2016) Diagnostic strategy and timing of intervention in infected necrotizing pancreatitis: an international expert survey and case vignette study. HPB 18(1):49-56

44. Nieuwenhuijs VB, Besselink MGH, Van Minnen LP, Gooszen HG (2003) Surgical management of acute necrotizing pancreatitis: a 13year experience and a systematic review. Scand J Gastroenterol Suppl 239:111-116

45. Sarr MG, Nagorney DM, Mucha P, Farnell MB, Johnson CD (1991) Acute necrotizing pancreatitis: management by planned, staged pancreatic necrosectomy/debridement and delayed primary wound closure over drains. Br J Surg 78(5):576-581

46. Beger HG, Büchler M, Bittner R, Block S, Nevalainen T, Roscher R (1988) Necrosectomy and postoperative local lavage in necrotizing pancreatitis. Br J Surg 75(3):207-212

47. Büchler MW, Gloor B, Müller CA, Friess H, Seiler CA, Uhl W (2000) Acute necrotizing pancreatitis: treatment strategy according to th status of infection. Ann Surg 232(5):619-622

48. Del Castillo CF, Rattner DW, Makary MA, Mostafavi A, McGrath D, Warshaw AL (1998) Débridement and closed packing for the treatment of necrotizing pancreatitis. Ann Surg 228(5):676-684

49. Rodriguez JR, Razo AO, Targarona J, Thayer SP, Rattner DW, Warshaw AL et al (2008) Debridement and closed packing for sterile or infected necrotizing pancreatitis: insights into indications and outcomes in 167 patients. Ann Surg 247(2):294-299

50. Husu HL, Kuronen JA, Leppäniemi AK, Mentula PJ (2020) Open necrosectomy in acute pancreatitis-obsolete or still useful? World J Emerg Surg 15(1):21. https://doi.org/10.1186/s13017-020-00300-9

51. Block S, Maier W, Clausen C, Büchler M, Malfertheiner P, Beger HG (1985) Diagnosis of necrotising pancreatitis. Comparison of contrast-enhanced CT and ultrasound in a clinical study. Dtsch Med Wochenschr 110(21):826-832

52. London NJM, Neoptolemos JP, Lavelle J, Bailey I, James D (1989) Contrast-enhanced abdominal computed tomography scanning and prediction of severity of acute pancreatitis: a prospective study. Br J Surg 76(3):268-272

53. Balthazar EJ, Robinson DL, Megibow AJ, Ranson JHC (1990) Acute pancreatitis: value of CT in establishing prognosis. Radiology. 174(2):331-336 
54. Wang PF, Liu ZW, Cai SW, Su JJ, He L, Feng J et al (2018) Usefulness of three-dimensional visualization technology in minimally invasive treatment for infected necrotizing pancreatitis. World J Gastroenterol 24(17):1911-1918

55. van Santvoort HC, Besselink MGH, Horvath KD, Sinanan MN, Bollen TL, van Ramshorst B et al (2007) Videoscopic assisted retroperitoneal debridement in infected necrotizing pancreatitis. HPB. 9(2):156-159

56. Bang JY, Arnoletti JP, Holt BA, Sutton B, Hasan MK, Navaneethan U et al (2019) An endoscopic transluminal approach, compared with minimally invasive surgery, reduces complications and costs for patients with necrotizing pancreatitis. Gastroenterology. 156(4):1027-1040.e3

57. Van Santvoort HC, Bakker OJ, Bollen TL, Besselink MG, Ahmed Ali U, Schrijver AM et al (2011) A conservative and minimally invasive approach to necrotizing pancreatitis improves outcome. Gastroenterology. 141(4):1254-1263

58. Luckhurst CM, El Hechi M, Elsharkawy AE, Eid AI, Maurer LR, Kaafarani HM et al (2020) Improved mortality in necrotizing pancreatitis with a multidisciplinary minimally invasive step-up approach: comparison with a modern open necrosectomy cohort. J Am Coll Surg 230:873-883

59. Baron TH, DiMaio CJ, Wang AY, Morgan KA (2020) American Gastroenterological Association clinical practice update: management of pancreatic necrosis. Gastroenterology. 158(1):67-75.e1

60. Van Minnen LP, Besselink MGH, Bosscha K, Van Leeuwen MS, Schipper MEI, Gooszen HG (2004) Colonic involvement in acute pancreatitis: a retrospective study of 16 patients. Dig Surg 21(1): 33-38

61. Gao L, Zhang J-Z, Gao K, Zhou J, Li G, Li B-Q et al (2020) Management of colonic fistulas in patients with infected pancreatic necrosis being treated with a step-up approach. HPB (Oxford) 2020:S1365-182X(20)30108-8

62. Flati G, Andrén-Sandberg Å, La Pinta M, Porowska B, Carboni M (2003) Potentially fatal bleeding in acute pancreatitis: pathophysiology, prevention, and treatment. Pancreas. 26(1):8-14

63. Connor S, Alexakis N, Raraty MGT, Ghaneh P, Evans J, Hughes M et al (2005) Early and late complications after pancreatic necrosectomy. Surgery. 137(5):499-505

64. Neoptolemos JP, London NJM, Carr-Locke DL (1993) Assessment of main pancreatic duct integrity by endoscopic retrograde pancreatography in patients with acute pancreatitis. Br J Surg 80(1):94-99

65. van Dijk SM, Timmerhuis HC, Verdonk RC, Reijnders E, Bruno MJ, Fockens P et al (2019) Treatment of disrupted and disconnected pancreatic duct in necrotizing pancreatitis: a systematic review and meta-analysis. Pancreatology. 19(7):905-915

66. Da Costa DW, Bouwense SA, Schepers NJ, Besselink MG, Van Santvoort HC, Van Brunschot S et al (2015) Same-admission versus interval cholecystectomy for mild gallstone pancreatitis (PONCHO): a multicentre randomised controlled trial. Lancet 386(10000):1261-1268

67. Nealon WH, Bawduniak J, Walser EM (2004) Appropriate timing of cholecystectomy in patients who present with moderate to severe gallstone-associated acute pancreatitis with peripancreatic fluid collections. Ann Surg 239(6):741-751

Publisher's note Springer Nature remains neutral with regard to jurisdictional claims in published maps and institutional affiliations. 